UNIVERSIDADE DE BRASÍLIA - UNB

FACULDADE DE ECONOMIA, ADMINISTRAÇÃO, CONTABILIDADE E CIÊNCIA DA INFORMAÇÃO E DOCUMENTAÇÃO - FACE

\title{
RESERVAS INTERNACIONAIS BRASILEIRAS: CUSTO DE FINANCIAMENTO E NÍVEL ÓTIMO
}


GUSTAVO BALDOINO SANTOS MENEZES

\title{
RESERVAS INTERNACIONAIS BRASILEIRAS: CUSTO DE FINANCIAMENTO E NÍVEL ÓTIMO
}

\author{
Monografia apresentada ao Programa de \\ Pós-Graduação em Administração \\ (PPGA) da Faculdade de Economia, \\ Administração, Contabilidade e Ciência da \\ Informação e Documentação (FACE), da \\ Universidade de Brasília, como requisito \\ parcial à obtenção do grau de Especialista \\ em Orçamento e Finanças
}

Orientador: Otavio Ladeira de Medeiros

Brasília - DF 


\section{RESUMO}

O assunto Reservas Internacionais emergiu em tempos recentes e despertou o interesse de especialistas na elaboração de estudos para, dentre outros aspectos, formularem conhecimento quanto ao custo que essas reservas representam. Fator determinante que fez ressurgir trabalhos científicos nessa área do conhecimento foi a rápida e volumosa acumulação desses ativos por parte de países em desenvolvimento e, em particular, pelos países emergentes, entre eles o Brasil. Essa monografia tem por objetivo expor estudos relacionados ao tema e especificamente abordar o custo de financiamento e o nível ótimo das reservas brasileiras.

Palavras Chave: Reservas Internacionais; Custo de financiamento das reservas internacionais; Nível ótimo das reservas internacionais. 


\section{SUMÁRIO}

1 Introdução

2 Elementos teóricos preliminares.................................................................

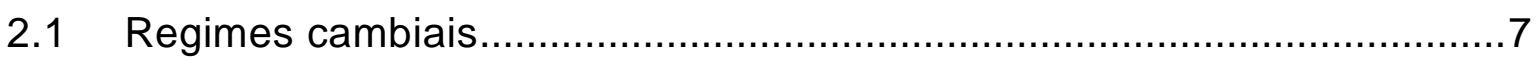

2.1.1 Regime de câmbio fixo..............................................................................

2.1.2Regime de câmbio flutuante ............................................................................

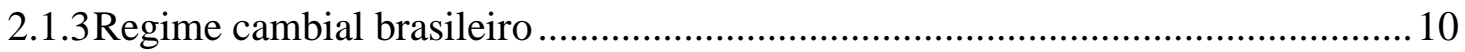

2.2 Regime de metas para a inflação …………......................................10

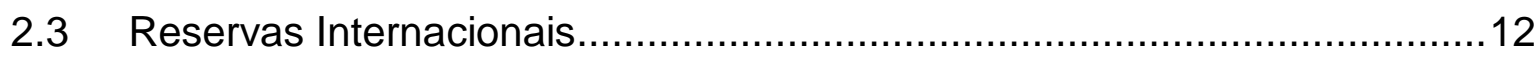

3 Contexto histórico das reservas internacionais ......................................13

4 Determinantes para o acúmulo de Reservas Internacionais.......................16

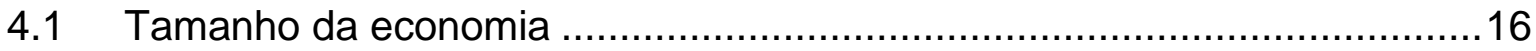

4.2 Vulnerabilidade da conta corrente ...................................................16

4.3 Vulnerabilidade na conta de capital ...................................................17

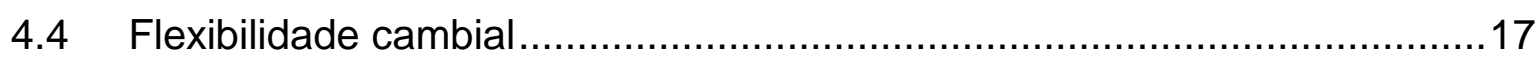

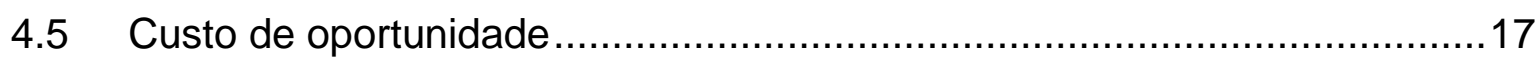

5 Motivadores para o acumulo de Reservas Internacionais .........................18

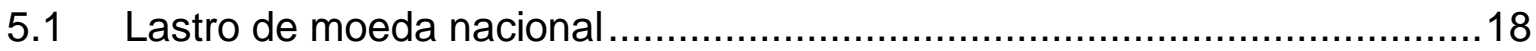

5.2 Instrumento de política cambial e monetária............................................19

5.3 Promoção de fundos para sanar compromissos financeiros externos ........19

5.4 Defesa contra emergências ou desastres ...............................................19

5.5 Fundo de investimento para ganho financeiro .......................................20

6 Custo financeiro das Reservas Internacionais............................................22 
6.1 Metodologia de Ramaswamy (2008) para o cálculo de custo financeiro líquido de financiamento de Reservas Internacionais....

$7 \quad$ Nível ótimo para Reservas Internacionais ....................................................29

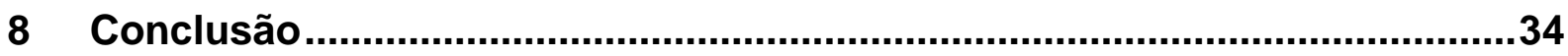

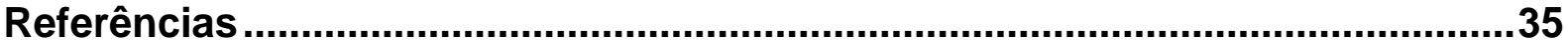




\section{Introdução}

Assunto recorrente desde a década de 1990 até os dias atuais em discussões relacionadas à economia das nações, Reservas Internacionais, Reservas Cambiais ou ainda Divisas, têm sido objeto de debates quanto à sua quantidade ideal. Essas discussões ganharam impulso com o volume de recursos que as reservas têm mobilizado nos últimos anos pelos países emergentes, entre eles o Brasil.

Um fato que muito tem preocupado os analistas econômicos é o custo financeiro e/ou de oportunidade que essas reservas representam aos países que as acumulam. Para muitos autores, seu valor equivale à diferença entre o quanto essas reservas auferem por seus investimentos externos e o quanto é pago por elas no mercado interno. Ramaswamy (2008, p.49) afirma que esse valor corresponde à "diferença entre o custo para financiá-las e seu retorno". Por outro lado, os recursos gastos com essas aquisições, segundo alguns economistas, poderiam ser aplicados em alternativas outras em benefício da sociedade.

O tema a ser abordado nesse trabalho é relativamente novo, conforme observado na literatura especializada: Salomão (2008); Cavalcanti e Vonbun (2008); além de Garcia (2006); dentre outros; e emergiu com maior destaque a partir da década de 1990, como observado por Lopes (2005, p.12) ao mencionar que "o tema vem chamando a atenção internacional devido à elevação dos níveis mundiais a partir da década de 90, tendência que ainda se intensificou em alguns países (especialmente na Ásia) após 2001". A acumulação de reservas internacionais por economias emergentes chamou a atenção de economistas e analistas financeiros em função de sua quantidade, levando a discussões e debates quanto ao seu excesso, considerado por alguns, e sua quantidade adequada, considerada por outros, suscitando uma necessidade de verificar seu custo de financiamento e seu nível ótimo.

No Brasil, esse debate tornou-se acalorado pela rápida acumulação de divisas, em anos recentes, pelo Banco Central do Brasil (BACEN) ${ }^{1}$. Esses ativos

\footnotetext{
${ }^{1}$ Ver em ANEXO A, gráfico que apresenta a evolução das reservas internacionais brasileiras.
} 
evoluíram de US $\$ 27.541^{2}$ milhões em 31 de Dezembro de 2004 para US $\$ 206.806$ milhões em 31 de Dezembro de $2008^{3}$.

Responder à questão de qual o custo referente ao financiamento das reservas internacionais brasileiras, elaborar uma contextualização histórica e estabelecer uma relação entre as reservas acumuladas pelo Brasil e sua quantidade adequada, constituem o objetivo desse estudo.

Portanto, em adição a este primeiro capítulo introdutório, nas páginas seguintes encontra-se uma abordagem conceitual contendo, ao todo, oito capítulos. No capítulo 2 foram apresentados os elementos teóricos preliminares que incluem os regimes cambiais, o regime de metas para inflação e conceitua reservas internacionais. A seguir, o capítulo 3 apresentou a contextualização histórica das reservas internacionais. Em seqüência, os capítulos 4 e 5 apresentaram determinantes e motivadores para o acúmulo de reservas. O custo financeiro e uma metodologia para o cálculo do custo de financiamento das reservas internacionais foram apresentados no capítulo 6 . Essa metodologia considera a variação cambial, para converter em moeda doméstica o resultado das aplicações dos ativos das reservas internacionais. No capítulo 7 foram apresentadas considerações sob pontos de vista diversos a respeito do nível ótimo para reservas internacionais. Para finalizar, a conclusão do trabalho foi apresentada no capítulo 8.

\footnotetext{
${ }^{2}$ Esse montante apresenta-se reduzido do aporte referente a empréstimo contraído com o FMI e representa o valor líquido ajustado. Desde a liquidação da dívida junto ao FMI, ocorrida em dezembro de 2005, não mais se aplica esse conceito.

${ }^{3}$ Fonte de dados: BACEN.
} 


\section{Elementos teóricos preliminares}

O crescente acúmulo de reservas internacionais por economias emergentes, em particular nos últimos anos pelo Brasil, tem suscitado discussões a respeito do custo de financiamento e do nível ótimo para essas reservas. Com o objetivo de responder "Qual o custo relacionado ao financiamento e qual o nível acumulado ideal para as Reservas Internacionais brasileiras", serão apresentados a seguir, elementos teóricos para subsidiar os estudos necessários à elucidação dessa questão.

\subsection{Regimes cambiais}

Numa economia comercial e financeiramente aberta ao resto do mundo, a moeda estrangeira surge como um novo ativo no mercado. Desta forma, é importante compreender como se dá a relação entre a moeda doméstica e a estrangeira. É no mercado de câmbio que estes dois ativos são trocados, e o preço da mercadoria nele negociada é denominada taxa de câmbio. Esta taxa corresponde ao valor da moeda estrangeira medido em unidades da moeda nacional. Portanto, uma desvalorização cambial corresponde a uma elevação da taxa de câmbio, enquanto que a apreciação cambial refere-se a uma queda desta taxa.

O regime cambial é determinado pela regra estabelecida para formação da taxa de câmbio. Em um regime de livre flutuação, a taxa de câmbio é definida através da operação das forças de mercado, em outras palavras, é formada pela interação das forças de oferta e procura. Como, em tese, o mercado agiria para regular a taxa de câmbio, reservas internacionais seriam desnecessárias. $O$ regime de câmbio fixo, por sua vez, possui relação entre moeda doméstica e estrangeira determinada por decisão do governo ou por uma lei, e não do mercado. Nesse regime, há ainda a necessidade de intervenção, pelo Banco Central, a fim de garantir a paridade fixa entre as moedas. Sendo assim, o Banco Central precisa dispor de reservas internacionais. 


\subsubsection{Regime de câmbio fixo}

O regime de cambio fixo vigorou tanto no século passado (sistema ouro) quanto no pós guerra, conhecido como período de Bretton Woods. Neste regime, o banco central assume o compromisso de comprar todo o excesso de oferta ou a suprir todo o excesso de demanda que existir no mercado cambial (ZINI JR,1996).

Observa-se que para ganhar confiança dos mercados, a operação do sistema de câmbio fixo demanda certa restrição sobre a emissão de moeda, salvo se isto for a contrapartida da acumulação de reservas internacionais, servindo para estimular a adoção de praticas anti-inflacionárias. Sob determinadas condições, a taxa de câmbio fixa representa um preço nominal importante que passa a servir como matriz na fixação dos preços internos. A taxa fixa pode ainda ser utilizada para emprestar credibilidade à promessa de combate à inflação pelos bancos centrais que tenham incorrido em políticas inflacionárias elevadas e/ou crônicas. Ainda neste sentido, quando do envolvimento em situações de desequilíbrio e instabilidade no mercado, emergidas a partir de especulações, uma taxa de cambio fixa pode dissuadir estas perturbações e favorecer a economia, se o país mantiver reservas suficientes.

Embora existam vantagens, o regime de taxa de câmbio fixa foi superado na prática, pois nenhum país conseguiu defendê-la por muito tempo sob condições de moeda fiduciária e políticas monetárias que se comunicam. Para manter o arranjo, os bancos centrais precisam manter reservas internacionais elevadas (ZINI JR, 1996).

Por fim, Hillbrecht (1999) salienta que outro aspecto negativo está relacionado com a rigidez do regime de cambio fixo, devido à necessidade de impor ajuste muito forte ao lado real da economia. O nível de empregos doméstico precisa ser expandido ou contraído como variável de ajuste quando é necessário ajustar as contas correntes. Mas, fazer recair o ajustamento externo sobre o nível de atividade interna mostrou-se politicamente inviável nos países democráticos. 


\subsubsection{Regime de câmbio flutuante}

Qualquer regime de concorrência manipulada seria inócuo e ineficaz num contexto onde os agentes envolvidos nas operações cambiais estabelecessem relações por meio de uma complexa e atuante rede de informações, rede essa, onde supostamente todos possuíssem, a qualquer instante, total acesso às condições operacionais vigentes. Alem disso, para completar o cenário, a oferta e demanda por divisas seria exercida por elevado número de compradores e vendedores independentes, sem que nenhum deles reunisse recursos suficientes para alterar as condições vigentes no mercado, quanto aos regimes de oferta e procura e cotações resultantes.

Sob essas hipóteses, e não havendo intervenção das autoridades monetárias, as formas de atuação das forças de oferta e procura por divisas estrangeiras conversíveis caracterizariam um mercado de estrutura bastante próxima da concorrência perfeita e, conseqüentemente, haveria uma cotação de equilíbrio. (ROSSETTI, 1982).

No regime de taxa de cambio de livre flutuação, por definição, o banco central não intervém no mercado cambial. Sem a necessidade de dispor de reservas internacionais, a taxa de cambio é definida através da operação das forças de mercado, ou seja, a taxa de cambio é formada pela interação das forças de oferta e procura (DE CARVALHO et al, 2001).

Para Rossetti (1982), a globalização dos mercados financeiros e conseqüentes exigências por flexibilidade, associadas aos três argumentos apresentados abaixo, representam razões que extrapolam os ajustes automáticos proporcionados pelas flutuações do câmbio para a adoção de regimes cambiais com taxas flexíveis:

- A adoção de regime de câmbio flutuante ou flexível liberta as autoridades monetárias quanto à necessidade de manter reservas. Pois, sob esse regime, o mercado cambial encontra seu auto-equilíbrio. Conseqüentemente, estas autoridades têm seu grau de liberdade ampliado para usar a política monetária na condução de outros objetivos da política econômica; 
- Em mercados sob flutuação, movimentos especulativos tendem a ter e a exercer funções muito mais na direção da estabilização do que no sentido contrário. A eficiência decorrente de uma atuação mais livre dos agentes econômicos ${ }^{4}$ tende a ser superior à obtida em mercados administrados;

- A taxa de câmbio flutuante não constitui único instrumento de ajuste dos fluxos externos e de equilíbrio do balanço de pagamentos, tanto em transações correntes quanto em movimentos de capital. ${ }^{5}$

\subsubsection{Regime cambial brasileiro}

O Brasil adotou, durante duas décadas e meia, um regime de minidesvalorizações cambiais passivas com o objetivo de manter estável a taxa de câmbio real. Com o Plano Real, o governo adotou a política de âncora cambial, na qual a taxa de câmbio era desvalorizada em pequenos intervalos. O objetivo dessa política era romper com as instituições do passado inflacionário, caracterizado pela indexação de preços e rendimentos, inclusive da taxa de câmbio. Essa política ficou conhecida como de câmbio semifixo ou regime de bandas cambiais, pois, mesmo sob regime de taxa de câmbio fixa, havia uma pequena margem de flutuação. Em 1999, o Brasil passou para o regime de câmbio flutuante, pois já vinha ocorrendo perda das reservas, de modo que o estoque remanescente não era suficiente para manter o regime anterior.

\subsection{Regime de metas para a inflação ${ }^{6}$}

Após vários anos de elevado crescimento econômico, a década de 1980 foi marcada pela conjunção de dois fatores: forte queda da taxa de crescimento da

\footnotetext{
${ }^{4}$ Esses agentes desenvolvem mecanismos para se proteger de choques imprevisíveis.

${ }^{5}$ Há instrumentos monetários, fiscais e administrativos que também podem ser utilizados para ajustar os fluxos externos, compatibilizando-os aos demais objetivos da política econômica.

${ }^{6}$ Fonte: BACEN.
} 
economia brasileira; e grande aumento da taxa de inflação, situação que se estendeu durante a primeira metade dos anos 90. A estabilidade de preços é condição necessária para que possa haver crescimento auto-sustentado. Além disso, no médio e longo prazo, maior inflação não gera maior crescimento, pelo contrário, cria um ambiente desfavorável aos investimentos e penaliza as camadas mais pobres da sociedade, promovendo concentração de renda.

No início de março de 1999, num ambiente ainda marcado pela incerteza quanto aos impactos da desvalorização do real sobre a inflação, o governo brasileiro anunciou a intenção de passar a conduzir a política monetária com base no arcabouço de metas para a inflação. Em $1^{\circ}$ de julho de 1999, o Brasil adotou formalmente o regime de metas para a inflação como diretriz da política monetária.

O regime de metas para a inflação é um regime monetário no qual o Banco Central se compromete a atuar de forma a garantir que a inflação observada esteja em linha com uma meta pré-estabelecida, anunciada publicamente.

O regime de metas para a inflação caracteriza-se geralmente por quatro elementos básicos:

i) Conhecimento público de metas numéricas de médio-prazo para a inflação;

ii) Comprometimento institucional com a estabilidade de preços como objetivo primordial da política monetária;

iii) Estratégia de atuação pautada pela transparência para comunicar claramente ao público sobre os planos, objetivos e razões que justificam as decisões de política monetária; e

iv) Mecanismos para tornar as autoridades monetárias responsáveis pelo cumprimento das metas para a inflação.

Adicionalmente ao anúncio público de metas numéricas para a inflação, são elementos essenciais desse regime, a transparência e a prestação de contas regulares à sociedade e aos seus representantes. 


\subsection{Reservas Internacionais}

O sistema monetário vigorante do século XIX até a Primeira Guerra Mundial era o padrão-ouro. Mas, ao final da Segunda Guerra Mundial, após os acordos de Bretton Woods, os Estados Unidos da América fixaram o valor do dólar ao do ouro, e permitiram a conversibilidade de dólares em ouro. Isto fez com que o dólar fosse visto efetivamente como um equivalente do ouro. Em 1971, durante o governo de Richard Nixon, os Estados Unidos da América abandonaram o sistema de Bretton Woods, mas o dólar permaneceu como uma moeda estável e fiduciária, e ainda hoje é a mais importante moeda de reserva, apesar de os bancos centrais manterem reservas compostas de múltiplas moedas.

Reservas Internacionais são os depósitos em moeda estrangeira dos bancos centrais e autoridades monetárias mantidos em ativos de países que constituem referência para essas aplicações ou por um portfólio ${ }^{7}$ mais diversificado, podendo incluir depósitos no Fundo Monetário Internacional (FMI), Bank for International Settlements (BIS), dentre outros, porém, preservando principalmente segurança e liquidez. Esses ativos são utilizados no cumprimento dos compromissos financeiros, como lastro para a emissão de moeda, balaço de pagamentos e para garantir as diversas reservas bancárias mantidas num banco central por governos ou instituições financeiras, dentre outras finalidades que também serão abordadas nesse estudo.

\footnotetext{
${ }^{7}$ Ver em ANEXO B tabela contendo portfólio de reservas internacionais brasileiras, administrado pelo BACEN.
} 


\section{Contexto histórico das reservas internacionais}

Desde os anos 1960 e 1970, economistas têm dedicado atenção ao estudo das reservas internacionais. Nesse período, quando estava vigente o arranjo cambial do sistema de Bretton Woods, a motivação principal para acúmulo de reservas estava em amortecer ou suavizar as variações no balanço de pagamentos, característica essa conhecida como função "buffer" das reservas. Esse fator fazia muito sentido no contexto de câmbios controlados da época, onde o equilíbrio do balanço, relacionado com os desbalanceamentos na conta corrente $e$, principalmente na conta de capitais, seria conseguido com a variação das reservas e não por ajuste no câmbio real.

Poucos foram os estudos relacionados às reservas a partir de meados da década de 1970 e por toda a década de 1980. Recentemente, no entanto, o interesse a respeito do tema foi retomado em resposta à forte acumulação de divisas pelos países em desenvolvimento em geral e pelos países emergentes em particular. No entanto, sob um novo ângulo, reservas agora são encaradas adicionalmente como meio para reduzir a incidência de crises internacionais.

Após o fim do sistema de Breton Woods e conseqüente flexibilização dos regimes cambiais de alguns países, as reservas tenderiam a perder importância, pois se aguardava que os ajustes do balanço de pagamentos fossem feitos via câmbio real, por atuação direta na conta corrente e nos fluxos de capitais. Movimento não confirmado ao observar-se o acúmulo das reservas em momento posterior, quando surgem explicações para esse comportamento, destacando-se o fato de regimes de câmbio flutuante nem sempre serem limpos, mas sim "dirty floats" ou flutuações sujas, onde as autoridades monetárias não fixam explicitamente o câmbio, mas alteram a cotação natural da moeda através de operações no mercado, em momentos por essas considerados oportunos.

Após a seqüência de crises financeiras nos anos 1990, países emergentes adotaram estratégias de retenção de altos níveis de moeda estrangeira de forma a contar com moeda conversível e agir como seu próprio financiador durante turbulências externas. A retenção de reservas internacionais tem sido interpretada 
como um objetivo de um país reduzir sua exposição à futuras paradas súbitas e crises financeiras.

A magnitude e a velocidade com que ocorreram reversões nos fluxos de capitais que surpreenderam a maioria dos especialistas durante a crise asiática em 1997-98, levaram ao questionamento dos mecanismos de política econômica adotados por esses países. Desde então, política externa no mundo emergente começa a ser mais baseada em um gerenciamento mais ativo das reservas cambiais. Esse foi o caso mesmo para aqueles países asiáticos antes considerados menos sujeitos a crises externas, já que contavam com maior abertura comercial, políticas fiscais sadias e robusto desempenho econômico antes da crise de 1997. Entretanto, os fatos mostraram que eles não estavam imunes aos efeitos colaterais relacionados a movimentos abruptos de capitais, incluindo rápidas contrações no investimento e renda, assim como crises em seus sistemas bancários. Portanto, a auto-proteção tem sido construída via aumento de reservas.

No começo do século XXI, o grande volume de liquidez internacional e a facilidade com que fluxos financeiros se movem de um país a outro, indicam uma maior globalização dos mercados, relativamente ao verificado nos anos 1990, parcialmente explicando a racionalidade para níveis mais elevados de reservas. Isso corrobora a hipótese de que hoje países emergentes estão ainda sujeitos, se não mais, a efeitos colaterais de crises financeiras, afetando todos os mercados mais ou menos desenvolvidos, mesmo que seja difícil de mensurar a probabilidade de ocorrência e o tamanho do próximo choque de liquidez.

As reservas internacionais constituem hoje, ativos soberanos afetando a exposição de um país em desenvolvimento ao risco-soberano e a ajustamentos custosos. Uma lição decorrente das crises financeiras, prevista por Aizenman, Lee e Rhee (2004) é que autoridades monetárias devem cuidadosamente observar os fluxos de capitais e ajustar os níveis de reservas internacionais às suas obrigações externas de curto prazo (GREENSPAN, 1999; GUIDOTTI, STURZENEGGER e VILLAR, 2004). As crises financeiras dos anos 1990 revelaram o limitado acesso de países emergentes a linhas de crédito internacionais, implicando uma necessidade independente de reservas nessas economias. A mudança política de postura do FMI, fechando as linhas de crédito emergenciais a países-membros após a crise Argentina (2001), apontou a relevância de acumular reservas em tal cenário. As reservas internacionais podem, inclusive, ser vistas como uma poupança 
precaucional para essas economias com acesso condicional aos mercados de capitais globais. (LAAN, 2008). 


\section{Determinantes para o acúmulo de Reservas Internacionais}

Conforme mencionado por Gosselin e Parent (2005) e reportados na literatura, os determinantes para a manutenção de reservas podem ser agrupados nas seguintes cinco categorias:

1. Tamanho da economia;

2. Vulnerabilidade da conta corrente;

3. Vulnerabilidade na conta de capital;

4. Flexibilidade cambial; e

5. Custo de oportunidade que as reservas representam.

\subsection{Tamanho da economia}

Produto Interno Bruto (PIB) e PIB per capta são indicadores usados para definir o tamanho de uma economia. Quanto maior o valor desses indicadores, maior potencial uma economia possui para acumular reservas. Portanto, economias maiores tendem a acumular montantes maiores de reservas e o incremento desses indicadores, conseqüentemente, dá margem a potencial crescimento das divisas acumuladas.

\subsection{Vulnerabilidade da conta corrente}

O montante acumulado em reservas apresenta sensibilidade às variações na balança comercial e a vulnerabilidade da conta corrente pode ser identificada pelo grau de abertura comercial e pela volatilidade das exportações. 


\subsection{Vulnerabilidade na conta de capital}

Com maior abertura financeira e/ou maior potencial para remessa de capital por residentes de um país, mais alta a vulnerabilidade na conta de capital e conseqüentemente maior demanda por reservas.

\subsection{Flexibilidade cambial}

A adoção de uma política de câmbio flutuante, em tese, não exigiria maiores preocupações com o acúmulo de reservas, pois o mercado se ajustaria livremente ao novo contexto, excluindo a necessidade de acúmulo de reservas para essa finalidade. No entanto, existe um medo de flutuar em algumas economias, "fear of floating", fato que leva ao acúmulo de reservas e caracteriza um regime de flutuação suja, "Dirty floating".

\subsection{Custo de oportunidade}

Existe um custo de oportunidade em relação ao acúmulo de reservas, pois, alternativamente a custear sua aquisição e manutenção, os recursos utilizados poderiam ser alocados em infra-estrutura e/ou alternativas outras em benefício da sociedade. Tal análise é realizada por Houner (2005 apud SALOMÃO, 2008, p. 18) ao defender que "as reservas têm custo de oportunidade porque estas poderiam alternativamente ser utilizadas para financiar investimentos públicos e pagar a dívida externa". 


\section{Motivadores para o acumulo de Reservas Internacionais}

Para Nugée (2000), embora quase todos os países acumulem divisas, seus motivos para mantê-las são diferentes. Além do mais, antes de definir uma política estratégica para as reservas, é necessário estabelecer precisamente a motivação para armazená-las. Só então pode haver um debate sobre seu nível ótimo, seu financiamento e seus investimentos.

Em sua análise, Nugée (2000) apresenta algumas das principais razões, dentre outras possíveis, para acumular reservas:

1. Utilização de reservas para lastro de moeda nacional;

2. Instrumento de política cambial ou monetária;

3. Promoção de fundo para saneamento de compromissos externos;

4. Defesa contra emergências ou desastres; e

5. Fundo de investimento para ganho financeiro.

\subsection{Lastro de moeda nacional}

A despeito de ser um uso tradicional para reservas, especialmente reservas em ouro, utilizá-las como lastro para a moeda nacional não constitui, nos dias de hoje, para a maioria dos países, a sua principal finalidade. Esse instrumento teve seu auge com o padrão ouro e sobreviveu após a segunda guerra mundial por meio do sistema de Bretton Woods. Após a quebra desse sistema, essa prática ficou pouco comum. 


\subsection{Instrumento de política cambial e monetária}

O uso das reservas como instrumento de política cambial ou monetária tem como exemplos:

i) A intervenção em mercado local de câmbio efetuada por autoridades de países que adotam política de câmbio flutuante, conduzindo a uma flutuação suja de câmbio, "Dirty Float"; ou

ii) A promoção de sub-valorização da moeda local através da compra principalmente de títulos do tesouro norte americano, com o objetivo de ganho de competitividade comercial externa, correspondendo a uma política mercantilista, no geral adotada por países asiáticos possuidores de forte perfil exportador.

\subsection{Promoção de fundos para sanar compromissos financeiros externos}

Para promover continuidade no balaço de pagamentos, é importante dispor de recursos que atendam às necessidades mínimas quanto às contas para o comercio de exportação, bem como para as contas do mercado de capitais. Dessa forma, se proporciona estabilidade e garante a confiança dos agentes econômicos.

\subsection{Defesa contra emergências ou desastres}

Quanto a emergências ou desastres, em face de um cenário onde predomina uma desregulamentação financeira global, países emergentes lançam mão de 
grandes volumes acumulados de reservas para defender-se da volatilidade dos fluxos financeiros internacionais ${ }^{8}$.

Essa atitude correspondente ao uso das reservas como seguro ou autoseguro, que pode ser utilizado em determinados momentos pelas autoridades monetárias, como relata Cavalcanti e Vonbun (2008, p. 464), ao dizerem que, na opinião de alguns economistas, o volume atualmente acumulado de reservas seria importante e necessário como um "seguro contra crises internacionais", fato que caracteriza uma política precaucional na utilização de reservas.

Como exemplo de utilidade e seguro que as reservas podem oferecer estão os momentos de crise de diversas naturezas, como crises de paradas repentinas no ingresso de capital na economia, assunto abordado por Lopes (2005) quando afirma que um argumento tradicional a favor do acúmulo de reservas internacionais está associado ao seu impacto em paradas súbitas no ingresso de capital em um economia, denominado sudden stops. Pois, "para o equilíbrio do Balanço de Pagamentos, a contrapartida seria uma combinação de reversão em conta corrente e redução das reservas" (LOPES, 2005, p. 12), possibilitando a um país que tenha acumulado divisas poder gastá-las em uma eventual crise para supostamente poupar a economia de um ajuste muito agressivo e custoso em conta corrente.

\subsection{Fundo de investimento para ganho financeiro}

São poucas as economias que poderiam fazer uso de reservas como fundo de investimento para ganho financeiro. No geral, o rendimento auferido pela aplicação dessas é reduzido perante os compromissos assumidos no mercado local para financiá-las. No entanto, para alguns países, um fundo de investimento pode ser uma política lógica em casos onde a economia local não pode absorver mais investimentos sem que haja um sobreaquecimento, onde outras formas de lucro ou rendimento poderiam desequilibrar a economia doméstica, ou preparar-se para um futuro sabidamente menos afortunado como no caso de esgotarem-se recursos

\footnotetext{
${ }^{8}$ Banco Mundial (2005).
} 
naturais finitos, bem como, essa aplicação pode diversificar os ativos de uma pequena economia. 


\section{Custo financeiro das Reservas Internacionais}

Nugée (2000) ressalta que há muita discussão a respeito do correto investimento das reservas, mas pouca se fala sobre a forma de aquisição dos ativos que as compõem, e afirma que esse ponto de vista também deve ser considerado para uma abordagem mais abrangente e identificação do verdadeiro custo de aquisição e armazenamento das reservas internacionais.

São três os métodos que, de forma geral, existem para financiar reservas: contrair empréstimos em moeda estrangeira por emissão formal de títulos em mercado internacional; obter empréstimos em moeda estrangeira contra moeda nacional por meio do mercado local de troca, swap cambial; ou, comprá-las diretamente no mercado contra moeda nacional. Há, em comum nestes três métodos, o fato de as autoridades monetárias não adquirirem ativos aleatoriamente em qualquer moeda. A aquisição de ativos em moeda estrangeira representa uma decisão consciente e bem calculada que leva em consideração a segurança, a liquidez, e em menor escala, o retorno que esses ativos podem proporcionar.

São distintos os efeitos perante o mercado local provocados por cada um desses métodos de aquisição:

i) Contração de empréstimo, quer por meio da emissão de títulos em mercado externo para captar moeda estrangeira, ou qualquer outro meio como, por exemplo, um empréstimo internacional, não afeta diretamente a taxa de câmbio. Nestes casos, não houve operação em moeda local, e por isso não deve haver qualquer efeito direto sobre ela;

ii) Swap cambial, por sua vez, traz efeito temporário para o mercado de câmbio. Apesar de ocorrer uma transação de compra de moeda estrangeira contra venda de moeda nacional, há uma liquidação futura igual e oposta. Portanto, não afeta o nível geral da taxa cambial;

iii) Já a compra direta de moeda estrangeira contra a venda de moeda nacional pode afetar o mercado de câmbio por aumento permanente de moeda 
nacional no mercado doméstico, fato que pode levar a uma prática colateral por parte das autoridades monetárias, ou seja, a esterilização monetária.

Políticas de esterilização e preocupações quanto à estabilidade monetária estão associadas e envolvem custos fiscais. A compra direta de moeda estrangeira aumenta a base monetária. Esse ato adiciona volume ao meio circulante e dessa forma injeta liquidez na economia, introduzindo uma pressão baixista à taxa juros doméstica. Isso pode ser conflitante com o regime de metas de inflação. A esterilização é feita ao predominarem essas configurações. No geral, os bancos centrais conduzem esse processo vendendo títulos de seu portfólio próprio ou pela venda de títulos em moeda local como, por exemplo, notas do banco central ou títulos do tesouro nacional, pagando juros para reduzir o excesso de liquidez. Como resultado, há o enxugamento da moeda introduzida na economia pela aquisição de reservas e, conseqüente, manutenção da base monetária. Dessa forma, a entrada de capital na economia não altera o volume de moeda em circulação. (LANN, 2008)

Analisar o financiamento das reservas por meio do ponto de vista apresentado permite a verificação de seu custo real e pode evidenciar tanto os ganhos quanto as perdas, especialmente nos casos onde, comparativamente, ativos estrangeiros de baixo rendimento são financiados com empréstimos domésticos de alto custo. Além do mais, pode mostrar que um retorno positivo pode não ser tão positivo quanto poderia ser. A questão chave é quando maiores retornos poderiam ser obtidos, após análise de risco, caso esses recursos fossem alocados em investimentos em infra-estrutura para o país.

A escolha por qual dos métodos a serem utilizados para financiar as reservas depende de fatores como a percepção do mercado de câmbio, do estado do mercado externo e a habilidade das autoridades monetárias para contrair empréstimos. As autoridades lançarão mão desses três métodos em tempos distintos, dependendo do custo relativo de cada um, do estado do mercado e da interação com outras políticas, configurando um cenário de decisão de grande complexidade e responsabilidade. (NUGÉE, 2000)

Para exemplificar, a Tabela 1 abaixo mostra o custo incorrido no financiamento dessas divisas no intervalo entre os anos 2000 e 2008 . Esses valores são decorrentes das decisões tomadas pelas autoridades monetárias responsáveis por administrar as reservas internacionais brasileiras. Em sua maioria, os resultados 
são negativos e representam um esforço fiscal para a manutenção dessas reservas cambiais. No entanto, esse esforço pode ser encarado como o equivalente ao pagamento de um prêmio de seguro, o qual estará disponível para ser utilizado em momentos críticos. Como ocorre com o seguro de nossos carros, pagamos para não ser usado, mas caso necessário, estaremos garantidos para aqueles sinistros contratados.

Tabela 1 - Custo de financiamento das reservas internacionais brasileiras administradas pelo BACEN. (R\$ mil)

\begin{tabular}{|c|c|c|c|}
\hline \multirow{3}{*}{2000} & \multirow{3}{*}{-112.539} & \multicolumn{2}{|c|}{2000} \\
\hline & & 10 Sem & -1.156 .650 \\
\hline & & 20 Sem & 1.044 .111 \\
\hline \multirow{3}{*}{2001} & \multirow{3}{*}{5.169 .272} & \multicolumn{2}{|c|}{2001} \\
\hline & & 10 Sem & 4.887 .792 \\
\hline & & 20 Sem & 281.480 \\
\hline \multirow{3}{*}{2002} & \multirow{3}{*}{18.740 .804} & \multicolumn{2}{|c|}{2002} \\
\hline & & 10 Sem & 3.909 .208 \\
\hline & & $20 \mathrm{Sem}$ & 14.831 .596 \\
\hline \multirow{3}{*}{2003} & \multirow{3}{*}{$-26.824 .352$} & \multicolumn{2}{|c|}{2003} \\
\hline & & 10 Sem & -28.898 .140 \\
\hline & & $20 \mathrm{Sem}$ & 2.073 .788 \\
\hline \multirow{3}{*}{2004} & \multirow{3}{*}{$-15.781 .846$} & \multicolumn{2}{|c|}{2004} \\
\hline & & 10 Sem & 431.964 \\
\hline & & $20 \mathrm{Sem}$ & -16.213 .810 \\
\hline \multirow{3}{*}{2005} & \multirow{3}{*}{$-33.411 .344$} & \multicolumn{2}{|c|}{2005} \\
\hline & & 10 Sem & -26.452 .734 \\
\hline & & $20 \mathrm{Sem}$ & -6.958 .610 \\
\hline \multirow{3}{*}{2006} & \multirow{3}{*}{$-16.900 .422$} & \multicolumn{2}{|c|}{2006} \\
\hline & & 10 Sem & -12.008 .520 \\
\hline & & $20 \mathrm{Sem}$ & -4.891 .902 \\
\hline \multirow{3}{*}{2007} & \multirow{3}{*}{$-43.209 .991$} & \multicolumn{2}{|c|}{2007} \\
\hline & & 10 Sem & -28.244 .651 \\
\hline & & $20 \mathrm{Sem}$ & -14.965 .340 \\
\hline \multirow{3}{*}{2008} & \multirow{3}{*}{ 121.289.632 } & \multicolumn{2}{|c|}{2008} \\
\hline & & 10 Sem & -39.580 .153 \\
\hline & & $20 \mathrm{Sem}$ & 160.869 .785 \\
\hline
\end{tabular}

Fonte: Demonstrações financeiras e contábeis do BACEN. 
Em seu estudo de como a diversificação de portfólio afeta o custo financeiro para as reservas internacionais, Ramaswamy (2008) apresenta uma metodologia de cálculo para estimar o custo financeiro líquido de um portfólio hipotético entre 19992007 para um conjunto de economias emergentes selecionadas, incluindo o Brasil.

No tópico seguinte, será apresentada esta metodologia juntamente com seu resultado calculado pelo autor, para um conjunto de 12 (doze) países.

\subsection{Metodologia de Ramaswamy (2008) para o cálculo de custo financeiro líquido de financiamento de Reservas Internacionais}

Por essa metodologia, o custo financeiro para as reservas cambiais, estimado em termos da moeda local, será igual à diferença entre o custo de financiamento doméstico e o rendimento auferido com a aplicação dos ativos que compõem as reservas, levando em consideração os juros e, ganhos ou perdas de capital.

Na metodologia proposta, é assumido que no início de cada quadrimestre a composição monetária das reservas será balanceada e investida para replicar o benchmark de investimento escolhido. Suponha que investimentos na $i$ ésima moeda estrangeira de composição do portfólio de investimentos, tenha m benchmarks para serem replicados. Esses benchmarks podem compreender títulos governamentais ou outras classes de ativos. Representando cada um desses benchmarks por $W_{i k} \mathrm{e}$ seu índice de retorno total no tempo $t$ por $l_{i k}(t)$, o índice do valor dos investimentos na $i$ ésima moeda de reserva no tempo $t+1$ será dado por:

$$
I_{i}(t+1)=I_{i}(t) \times\left(\sum_{k=1}^{m} w_{i k} \frac{I_{i k}(t+1)}{I_{i k}(t)}\right)
$$

Ao final de cada quadrimestre, o valor em moeda local dos investimentos feitos na i ésima moeda de reserva, dependerá de duas variáveis: O retorno total no índice de benchmark composto pelo ganho de capital mais os juros e, o regresso advindo da variação cambial. Suponha que $A_{i}(t)$ representa a quantidade equivalente de moeda local investida na i ésima moeda de reserva no tempo t e $S_{i}(t)$ representa 
a taxa de câmbio doméstica da i ésima moeda de reserva, ou seja, o número de unidades de moeda doméstica necessárias para a aquisição de uma unidade de moeda de reserva. Então, para um tempo $t+1$, ou seja, no quadrimestre seguinte, o valor em moeda doméstica desse investimento será:

$$
A_{i}(t+1)=A_{i}(t) \times \frac{l_{i}(t+1)}{l_{i}(t)} \times \frac{S_{i}(t+1)}{S_{i}(t)}
$$

O retorno de investimento da i ésima moeda de reserva durante o quadrimestre, em termos da moeda local, será dado por:

$\operatorname{Retorno}_{i}(t+1)=A_{i}(t+1)-A_{i}(t)$

O retorno total sobre os ativos das reservas em termos da moeda local será a soma dos retornos de cada moeda de reserva e é dado por:

Retorno $(\mathrm{t}+1)=$ RetornousD $(\mathrm{t}+1)+$ Retorno $_{\mathrm{EUR}}(\mathrm{t}+1)+\operatorname{Retorno}_{\mathrm{JPY}}(\mathrm{t}+1)+$ Retorno $_{\mathrm{GBP}}(\mathrm{t}+1)$

Pelo lado do passivo, representar o total de reservas no tempo t por $A(t)$ e a taxa de juros doméstica do trimestre por $\mathrm{R}(\mathrm{t})$, a despesa será:

Despesa $(t+1)=0,25 \times A(t) \times(R(t) / 100)$

Se PIB $(t+1)$ representa o PIB nominal a preço corrente em termos da moeda doméstica, então, o custo financeiro de um quadrimestre como percentagem do PIB é:

CustoFinanceiro $(t+1)=100 \times($ Despesa $(t+1)-$ Retorno $(t+1)) / P I B(t+1)$

Como resultado, o custo financeiro anualizado como percentagem do PIB será a soma desses custos por quatro trimestres consecutivos. Nesse caso, um valor positivo indicará uma perda de rendimento líquido para as reservas tendo como 
pressuposto que os ativos dessas reservas são totalmente decorrentes dos passivos domésticos, e por outro lado, um valor negativo representará um ganho para o banco central.

A Tabela 2 abaixo apresenta o resultado da aplicação da metodologia proposta para estimativa do custo financeiro médio anual de financiamento de reservas internacionais para o conjunto de 12 países listados.

Tabela 2 - Estimativas do custo financeiro médio anual para financiamento das reservas como percentagem do PIB nominal. Período: 1999-2007.

\begin{tabular}{|l|c|c|c|}
\hline \multirow{2}{*}{ País } & \multicolumn{3}{|c|}{ Custo Financeiro (benchmark) } \\
\cline { 2 - 4 } & \multicolumn{3}{|c|}{ Títulos de 1 a 3 anos } \\
\cline { 2 - 4 } & DEV* & FIX** & SDR*** \\
\hline Algeria & $-0,8$ & $-0,6$ & $-1,1$ \\
\hline Brasil & 1.0 & 1.1 & 1.0 \\
\hline China & 0.0 & 0,1 & $-0,2$ \\
\hline Índia & 0,3 & 0,4 & 0,2 \\
\hline Coréia & 0,4 & 0,5 & 0,3 \\
\hline Malásia & 0,2 & 0,3 & 0,0 \\
\hline México & 0,2 & 0,3 & 0,2 \\
\hline Nigéria & 1,1 & 1,2 & 1,0 \\
\hline Rússia ${ }^{9}$ & 0,7 & 0,8 & 0,6 \\
\hline África do Sul & $-0,1$ & $-0,1$ & $-0,1$ \\
\hline Taiwan, China & $-1,3$ & $-1,0$ & $-1,6$ \\
\hline Tailândia & $-0,1$ & 0,0 & $-0,2$ \\
\hline
\end{tabular}

* Composição de reservas cambiais dos países em desenvolvimento.

** Proporção fixa de $80 \%$ US dollars, $15 \%$ euros e 5\% libras esterlinas.

*** Composição da cesta de ativos SDR (Direito de saques especiais) .

Fontes: IMF; Bloomberg; JPMorgan Chase; Cálculos do autor (Ramaswamy)

Pelos resultados calculados, do conjunto de países considerados, Algeria, África do Sul, Taiwan (China) e Tailândia auferiram renda com a aplicação de suas reservas, ou seja, acumular divisas constituiu uma fonte adicional de receitas públicas para esses países emergentes. No entanto, essa condição constitui fato pouco comum, como já visto em momento anterior desse estudo.

\footnotetext{
${ }^{9} \mathrm{O}$ custo financeiro para o acúmulo de reservas estrangeiras para a Rússia é significativamente inferior ao aqui estimado. Pois, parte substancial de financiamento é feito por meio de tributação das receitas de petróleo.
} 
A China, segundo percentual calculado, não auferiu receita nem arcou com custo fiscal para os cofres públicos, pois, apresentou zero como resultado.

Mais natural, portanto, é o financiamento das reservas representar um custo fiscal para as nações que as acumulam, como se pode observar nos resultados do Brasil, Índia, Coréia, Malásia, México, Nigéria e Rússia.

Especificamente para o Brasil, segundo a metodologia empregada, no período compreendido entre 1999 e 2007 houve um custo financeiro estimado de $1,0 \%$ do PIB para cada ano, referente ao financiamento de suas reservas. Esse fato o destaca como um dos países que arcam com um dos maiores custos fiscais dentre os analisados no período, ficando à frente apenas da Nigéria, que apresenta o percentual de $1,1 \%$ do PIB ao ano, para esse custo. Isso pode ser explicado pela alta taxa de juros praticada no mercado doméstico, associada a uma substancial valorização do real desde o ano de 2003.

A crise iniciada no final de 2007 nos Estados Unidos da América, devido aos títulos imobiliários e seu alastramento por instituições financeiras predominantemente de países ricos, afetou a economia real dos demais países do globo, tendo atingido o Brasil principalmente a partir do quarto trimestre de 2008. Esta crise provocou uma desvalorização cambial e forçou uma baixa na taxa referencial de juros, mesmo que ainda elevada para os padrões mundiais. Esse contexto, levado ao cálculo proposto pela metodologia apresentada, a qual considera a variação do câmbio, as taxas domésticas de financiamento, bem como depreciações ou valorizações dos títulos aplicados, nos conduz a um cenário favorável em momento de crise. Neste cenário, a taxa de financiamento presumida das reservas como percentual do PIB tende ao recuo, podendo até atingir um valor negativo, corroborando com as estimativas do presidente do BACEN ${ }^{10}$ que em Dezembro de 2008 mencionou que o Brasil estava credor para com o custo das reservas para aquela ocasião. ${ }^{11}$

\footnotetext{
${ }^{10}$ A Tabela 1 apresenta, para o segundo semestre de 2008, resultado credor para o custo de financiamento das reservas internacionais brasileiras administras das pelo BACEN.

${ }^{11}$ Fonte: Jornal Gazeta Mercantil, 19 a 21.12.2008, pág. B1.
} 


\section{Nível ótimo para Reservas Internacionais}

Em relação direta com os determinantes, e identificados os motivadores para o acumulo de reservas internacionais, é momento para discussões a respeito de seu nível ótimo.

Nugée (2000) considera que divisas são ferramentas para as autoridades monetárias e devem ser manipuladas com sabedoria. Um aspecto relevante é a identificação de qual o mínimo necessário para corresponder às necessidades identificadas, sem, contudo, perder de vista os fatores determinantes que possui uma economia. Outro aspecto a ser considerado, é o custo relacionado ao financiamento das reservas. Portanto, identificá-lo representa um facilitador na condução das discussões sobe o nível ótimo. Juntos, esses dois elementos proporcionam um limite inferior para as reservas e uma pressão menor por elevá-las, sem limites, acima desse patamar.

No entanto, Nugée (2000) afirma não ser tarefa fácil determinar esse nível mínimo em função desse processo não ser uma ciência exata. Daí esse ser um dos motivos que levam muitos países a acumularem valores com uma margem confortável acima desse mínimo. Mas, é importante salientar que, apenas em raras exceções, as autoridades não fazem o seu melhor ao adquirirem reservas sem limites.

Lang (2006) argumenta que estabelecer o nível ótimo para as reservas internacionais é algo de fundamental importância, pois os montantes direcionados para esse fim são de grande relevância e, se bem dimensionados, podem afetar positivamente e trazer benefícios para toda a economia. Por outro lado, um mau dimensionamento "impõe uma série de deficiências econômicas e conseqüências que, caso não sejam tomadas medidas eficazes e tempestivas, acabam por contaminar todo o ambiente macroeconômico interno" (LANG, 2006, p.1).

Lang (2006) também coloca que alguns governos, por não se preocuparem com esse dimensionamento, pagam um alto preço. Quando estabelecem seu nível de reservas abaixo do ótimo, comprometem seu equilíbrio da balança de pagamentos. O oposto imobiliza recursos que poderiam ser mais bem utilizados, 
como em políticas de crescimento econômico sustentado, geração de emprego, desenvolvimento de setores, áreas ou regiões e, ainda, por auferir ganhos inferiores aos de mercado por suas aplicações.

Existem diversos métodos e modelos que tentam quantificar o nível ótimo de reservas internacionais de um país. Para isso, são utilizados indicadores ou regras de bolso como a de Guidotti/Greenspan, a qual prescreve um nível de reserva equivalente à dívida externa de curto prazo.

Como exemplos de indicadores utilizados para mensurar o nível ótimo de reservas internacionais de uma nação estão a razão entre as reservas e o PIB ou a razão entre estas e algum agregado monetário, o número de meses de importação a que as reservas equivalem, dentre outros.

Cavalcanti e Vonbun (2007) basearam seu trabalho em função do modelo desenvolvido por Ben-Bassat e Gottlieb (1992), que levam em consideração o risco soberano de "default" na definição da demanda por reservas devido a motivações precaucionais e fazem sua análise por uma ótica exógena, ao usarem o "spread" ou a diferença entre a taxa de juros sobre a dívida externa e a taxa de remuneração das reservas. No entanto, Cavalcanti e Vonbun (2007) estenderam esse modelo para o caso de um custo de oportunidade endógeno.

Jeanne e Ranciére (2006) desenvolveram um modelo micro-fundamentado de determinação de reservas ótimas, onde um maior volume de reservas permite atenuar os efeitos adversos de uma parada súbita no fluxo de capitais externos para o país. Já Lopes (2005), não define um nível ótimo para as reservas e contribui para enfraquecer a noção de que as reservas são necessárias para assegurar proteção contra reversões de fluxos de capitais.

Silva Jr, Cajueiro e Yoneyama (2004) identificam um efeito de realimentação entre o volume e o perfil da dívida pública e o nível de reservas cambiais, por meio de um modelo de controle estocástico ótimo no qual a acumulação de reservas seria usada para reduzir o risco de uma crise de default em momentos de deterioração de outros fundamentos. A compra ou venda de reservas seria, portanto, considerada endógena em relação às necessidades de se controlar os riscos da dívida e aos objetivos da política monetária. Por meio da utilização do modelo de Frenkel e Jovanovich (1981), os autores determinam o nível adequado de reservas no período entre janeiro de 1999 e agosto de 2004, chegando a resultados que sugerem que, a 
partir da segunda metade de 2002, as reservas brasileiras passaram a estar acima do ideal, na maior parte do tempo.

Silva Jr e Silva (2004) também empregam o modelo de Frenkel e Jovanovich (1981), calculando o estoque ótimo de reservas para o Brasil no período entre janeiro de 1995 e março de 2004 em função do desvio-padrão do resultado do balanço de pagamentos, do custo de ajustamento do nível de reservas, do total de importações e do custo de oportunidade das reservas - definido como uma média ponderada da diferença entre o retorno das reservas e os custos das dívidas externa e interna. De acordo com seus resultados, as reservas observadas encontravam-se abaixo do nível ótimo antes da desvalorização de janeiro de 1999; entre 1999 e 2004, sucederam-se períodos de "sobreacumulação" e de "subacumulação" de reservas; e, a partir de março de 2004, o país já possuía mais reservas do que o considerado ótimo.

Cavalcanti e Vonbun (2007) apresentam estimativas do nível ótimo de reservas para o Brasil no período 1999-2006 a partir de aplicações do modelo original de Ben-Bassat e Gottlieb (1992), doravente BG, e de sua extensão para o caso de um custo de oportunidade endógeno. De acordo com o modelo BG original, as reservas observadas no país encontravam-se, sob diversos cenários para a magnitude dos custos de uma crise de default, abaixo do nível ótimo até 2003-2004, tendo então ultrapassado o nível ótimo e se tornado crescentemente excessivas corroborando, nesse ponto, os resultados de Silva Jr e Silva (2004). Por outro lado, as conclusões a partir do modelo BG "modificado" variavam significativamente entre os cenários considerados: para custos de crise relativamente baixos, as reservas teriam estado acima do nível ótimo ao longo de todo o período analisado, enquanto para os cenários mais pessimistas de custos de crises as reservas observadas teriam estado próximas do ótimo, ou abaixo deste, na maior parte do tempo.

Cada um dos trabalhos mencionados nessa monografia utiliza um ou mais dos conceitos e indicadores anteriormente citados, na tentativa de determinar um nível ótimo de divisas a serem acumuladas. Para o caso brasileiro, muitos autores concluem que é demasiado o volume de reservas acumuladas pelo país.

Os agentes monetários de uma nação administram recursos que são custeados com o orçamento público e, portanto, representam a poupança de cada cidadão que contribui com seus impostos para o benefício da sociedade. A estabilidade macroeconômica é um fator que garante o bem estar e proporciona 
fundamentos para um crescimento sustentável e de longo prazo para uma economia. Logo, a cautela é predominante no pensamento dessas autoridades. Por essa perspectiva, surge um indicador mais conservador que os analisados na maioria dos estudos sobre o tema.

A razão das Reservas Internacionais (RI) pelo somatório da Dívida Externa de Curto Prazo mais os serviços da Dívida Externa de Médio e Longo Prazo para os 12 meses vincendos adicionados dos investimentos em carteira composta por títulos e ações de estrangeiros na bolsa, compõe este indicador.

Tabela 3 - Indicadores calculados para Reservas Internacionais brasileiras.

\begin{tabular}{|c|c|c|c|c|}
\hline Data & $\begin{array}{c}\text { RI/ } \\
\text { PIB }\end{array}$ & $\begin{array}{c}\text { RI/ } \\
\text { Import. } \\
\text { (3 meses) }\end{array}$ & $\begin{array}{c}\text { RI/ } \\
\text { Div. Ext. CP* }\end{array}$ & $\begin{array}{c}\text { RI/ } \\
\text { (Div. Ext. CP + } \\
\text { Serv Div MLP + } \\
\text { Carteira Estrangeira) }\end{array}$ \\
\hline Dez-00 & $5,1 \%$ & 2,2 & 1,2 & $\mathbf{0 , 4 5}$ \\
\hline Dez-01 & $6,5 \%$ & 2,9 & 1,3 & $\mathbf{0 , 5 2}$ \\
\hline Dez-02 & $7,5 \%$ & 3,3 & 1,6 & $\mathbf{0 , 5 5}$ \\
\hline Dez-03 & $8,9 \%$ & 3,7 & 2,4 & $\mathbf{0 , 6 2}$ \\
\hline Dez-04 & $8,0 \%$ & 3,0 & 2,8 & $\mathbf{0 , 6 4}$ \\
\hline Dez-05 & $6,1 \%$ & 2,8 & 2,9 & $\mathbf{0 , 5 7}$ \\
\hline Dez-06 & $7,9 \%$ & 3,5 & 4,2 & $\mathbf{0 , 6 0}$ \\
\hline Dez-07 & $13,5 \%$ & 5,2 & 4,6 & $\mathbf{0 , 6 5}$ \\
\hline Dez-08 & $12,3 \%$ & 4,6 & 5,3 & $\mathbf{1 , 0 9}$ \\
\hline
\end{tabular}

RI - Reservas Internacionais.

PIB - Produto Interno Bruto.

Div. Ext. CP - Dívida Externa de Curto Prazo.

Serv. Div. MLP - Serviço da Dívida de Médio e Longo Prazo que vence no curto prazo (12 meses).

* Regra Greenspan/Guidotti, nível ideal (mínimo) $=1$.

Observando-se os dados apresentados na Tabela 3 acima $^{12}$, segundo a perspectiva mencionada, apesar das críticas quanto à quantidade de divisas acumuladas pelo BACEN, havia margem para aumento das reservas do Brasil, ceteris paribus, em todo o período compreendido entre dezembro de $2000 \mathrm{e}$ dezembro de 2007. Fato que ocorreu em dezembro de 2008, quando o indicador apresentado apontou para o valor 1,09.

\footnotetext{
${ }^{12}$ Ver tabela completa em ANEXO C.
} 
É importante salientar que, dada a margem de $35 \%$ para o aumento no volume de reservas perante dezembro de 2007, o que houve foi um ligeiro incremento de aproximadamente $7 \%$. Dessa forma, a justificativa está na alteração de cenário proporcionada pela crise internacional vigente ao motivar os investidores estrangeiros a reduzirem significativamente seus investimentos em carteira, fator contribuinte em conjunto com a redução da dívida de curto prazo (12 meses) e também da dívida de médio e longo prazo com maturidade em 12 meses para a elevação do indicador.

Em sua dissertação de mestrado, Salomão (2008) cita dentre os indicadores mais populares, um que mais se aproxima do indicador mais conservador apresentado nesse trabalho: a razão entre as reservas e a dívida externa de curto prazo por maturidade residual. Conceito que inclui a dívida contratada no curto prazo e também as amortizações da dívida de médio e longo prazo. Porém, não considera os investimentos de estrangeiros em carteira compostos por títulos e ações na bolsa de valores. 


\section{Conclusão}

Essa monografia apresentou uma breve abordagem sobre Reservas Internacionais e buscou ampliar o conhecimento desse assunto, tendo em vista a escassa literatura a respeito. Para isso, fundamentou conceitos preliminares sobre regime cambial e regime de metas de inflação. Conceituou reservas expondo os fatores determinantes e motivos para seu acúmulo, bem como expôs uma metodologia para o cálculo do custo financeiro para financiamento dessas reservas e fez considerações a respeito de seu nível ótimo.

O custo financeiro para financiamento das reservas internacionais pode ser calculado pela metodologia apresentada nesse trabalho como por uma outra que já exista ou mesmo venha a surgir no futuro. No entanto, ficou evidenciado por meio da metodologia proposta que seu valor pode variar por alterações macroeconômicas, como pelo rendimento dos títulos onde as reservas são aplicadas, variação na taxa doméstica de financiamento e/ou variação na taxa de câmbio.

Quanto ao nível ótimo, observa-se que seu valor ideal pode variar em função da metodologia empregada, e estudos a respeito das reservas brasileiras, que no geral as consideram em excesso, podem apresentar outro resultado com a utilização de indicadores que pressuponham cenários e eventos mais conservadores.

Para futuros trabalhos fica a sugestão de relacionar as reservas internacionais acumuladas pelo Brasil e crises internacionais recentes, objetivando-se verificar seus efeitos sobre a estabilidade macroeconômica do país perante esses momentos. 


\section{Referências}

AIZENMAN, J.; LEE, Y.; RHEE, Y. International Reserves Management and Capital Mobility in a Volatile World: policy considerations an case study of Korea. NBER Working Paper, Cambridge, no. 10.534. Mass.: National Bureau of Economic Research, 2004.

BEN-BASSAT, A., GOTTLIEB, D. Optimal international reserves and sovereign risk. Journal of International Economics, v. 33, n. 3-4, (s.I.), p. 345-362, 1992.

CAVALCANTI, M. A. F. de H.; VONBUN, C. Reservas internacionais ótimas para o Brasil: uma análise simples de custo-benefício para o período 1999-2007. Economia Aplicada, São Paulo, Jul-Set. 2008, V.12, no. 3, p.463-498.

CAVALCANTI, M. A. F. de H.; VONBUN, C. Reservas internacionais ótimas para o Brasil: uma análise simples de custo-benefício para o período 1999-2007. Texto para discusão: IPEA, Rio de Janeiro, n. 1315, dez, 2007.

DE CARVALHO, F. J. C. et al. Economia monetária e financeira: teoria e política. 1.ed. Rio de Janeiro: Campus, 2000.

FRENKEL, J.; JOVANOVIC, B. Optimal International Resreves: A Stochastic Framework. Economic Journal, n. 91 June, p. 507-514, 1981.

GARCIA, M. G. P. Reservas Cambiais: Debate Carente de Números. Valor Econômico, Rio de Janeiro, 31 ago. 2006.

GOSSELIN, M. A.; PARENT, N. An Empirical Analysis of Foreign Exchange Reserves in Emerging Asia. Bank of Canada Working Paper, Ottawa, no. 38. Dec. 2005.

GREENSPAN, A. Currency Reserves and Debt. Remarks Before the World Bank Conference on Recent Trends in Reserves Management, Washington, D.C., April 29, 1999.

GUIDOTTI, P. E.; STURZENEGGER, F.; VILLAR, A. On the consequences of Sudden Stops, Economia, Journal of the Latin American and Caribbean Economic Association, 2004. 
HILLBRECHT, R. Economia Monetéria. 1.ed. São Paulo: Atlas, 1999.

JEANNE, O.; RANCIÉRE, R. The optimal level of international reserves for emerging market economies: formulas and applications. In: IMF Working Paper WP 06/229, Washington DC: IMF Research Department, Oct. 2006. 33p.

LAAN, C. R. V. D. Gestão cambial e de fluxos de capitais em economias emergentes: três ensaios sobre a experiência recente do Brasil. 2008. 215 f. Tese (Doutorado em Economia) - Universidade Federal do Rio Grande do Sul, Porto Alegre, 2008

LANG, G. L. O Nível Ótimo das Reservas Internacionais: evidências para o Brasil. 2006. 97 f. Dissertação (Mestrado em Economia) - Universidade de Brasília, Brasília, 2006.

LOPES, D. A. R. Reservas internacionais: proteção em sudden stops? 2005. $83 \mathrm{f}$. Dissertação (Mestrado em Economia) - Pontifícia Universidade Católica do Rio de Janeiro, Rio de Janeiro, 2005.

NUGÉE, j. Foreign Exchange Reserves Management. In: HEALEY, J. Handbooks in Central Banking. England: CCBS, 2000. no. 19, p. 6-14.

RAMASWAMY, S. Managing international reserves: how does diversification affect financial costs? BIS Quarterly Review, Basel, Jun. 2008. Disponível em: http://www.bis.org/publ/qtrpdf/r_qt0806.htm. Acesso em: 14 Jan. 2009.

ROSSETTI, J. P. A Taxa de Câmbio e o Balanço de Pagamentos. In. Introdução à Economia. 9.ed. São Paulo: Atlas, 1982. cap.33.2

SALOMÃO, J. T. Nível Ótimo de Reservas Internacionais para Economias Emergentes. 2008. 78 f. Dissertação (Mestrado em Economia) - Pontifícia Universidade Católica do Rio de Janeiro, Rio de Janeiro, 2008.

SILVA JR., A.; SILVA, E. D. Optimal international reserves holdings in emerging markets economies: the Brazilian case. In: ANPEC - Associação Nacional dos Centros de Pós-Graduação em Economia, 078. Anais do XXXII Encontro Nacional de Economia, João Pessoa. 2004.16p. 
SILVA JR, A.; CAJUEIRO, D.; YONEYAMA, T. Dívida pública, reservas cambiais e estratégia ótima em eventos de crises financeiras. Brasília: ESAF, 2004. 75 p. In: IX Prêmio Tesouro Nacional - 2004. Ajuste Fiscal e Dívida Pública, Brasília, DF, 2004.

ZINI JR, A. A. Política Cambial com Liberdade ao Câmbio. In. BAUMANN, R. (Org.). O Brasil e a Economia Global. Rio de Janeiro: Campus, 1996. p. 119-121. 


\section{ANEXO A - Evolução das Reservas Internacionais brasileiras.}

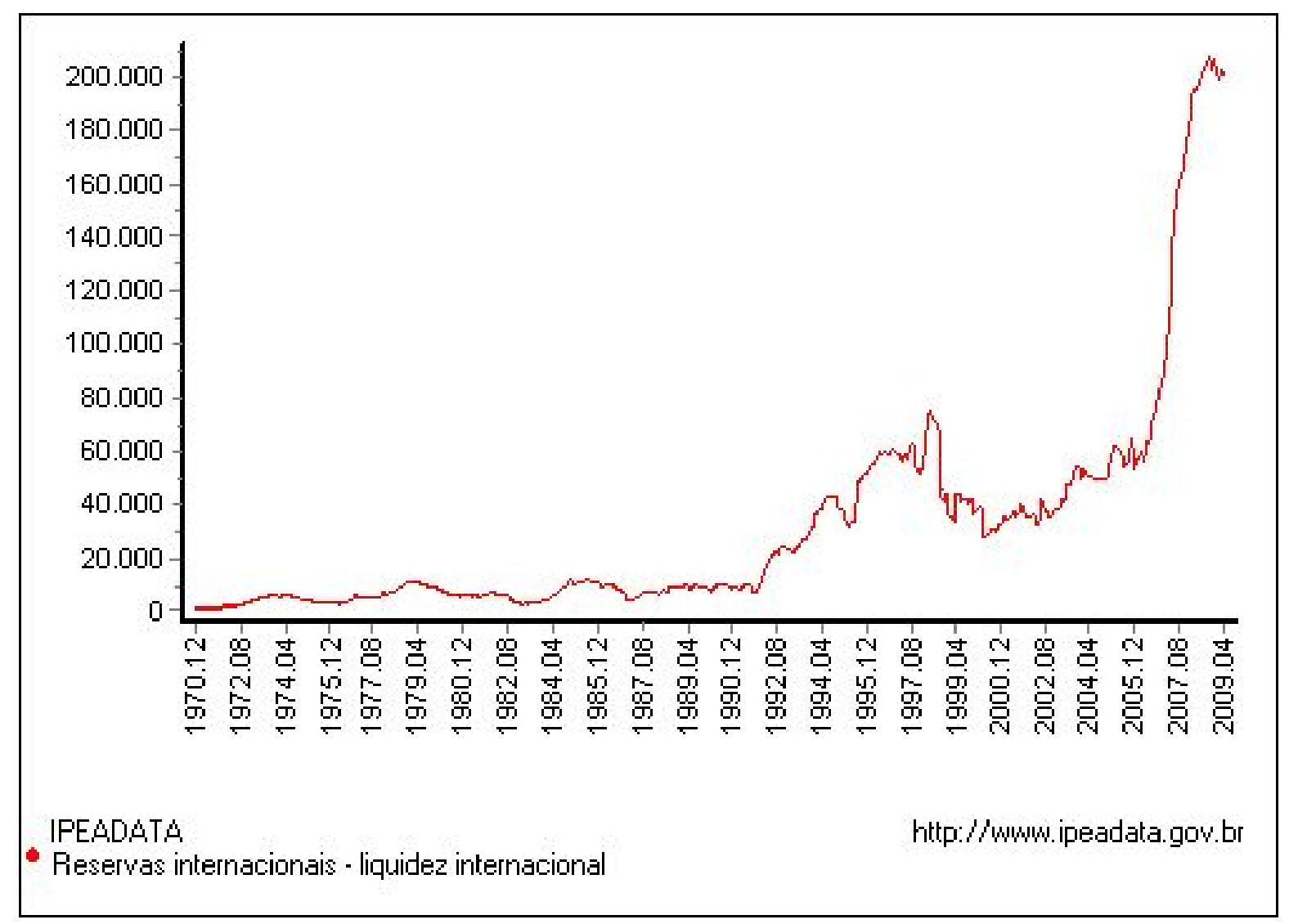

Reservas internacionais: liquidez internacional

Periodicidade: Mensal

Fonte: Banco Central do Brasil, Boletim, Seção Balanço de Pagamentos (BCB Boletim/BP)

Unidade: US\$(milhões)

Comentário: Quadro: Reservas internacionais no Banco Central do Brasil.

Atualizado em: 26 de maio de 2009 


\section{ANEXO B - Portfólio das Reservas Internacionais brasileiras mantidas pelo BACEN.}

\begin{tabular}{|c|c|c|c|c|}
\hline \multicolumn{5}{|c|}{ RESERVAS INTERNACIONAIS } \\
\hline \multicolumn{5}{|l|}{ Ativos de reservas oficiais } \\
\hline & \multicolumn{4}{|c|}{ Liquidez - US\$ milhões } \\
\hline & dez/06 & dez/07 & dez/08 & abr/09 \\
\hline Ativos de Reserva Oficiais ${ }^{1 /}$ & 85.839 & 180.334 & 193.783 & 190.546 \\
\hline - Reservas Líquidas Ajustadas (exclui empréstimo do FMI) ${ }^{2 /}$ & $\ldots$ & $\ldots$ & $\ldots$ & $\ldots$ \\
\hline - Reservas em moeda estrangeira (em divisas conversíveis) & 84.463 & 163.526 & 190.929 & 185.862 \\
\hline Q (a) Títulos & 71.043 & 156.057 & 188.746 & 182.761 \\
\hline$\square$ dos quais: emissor sediado no Brasil, mas domiciliado no exterior & 1.112 & - & - & 0 \\
\hline ㅁ (b) Total de moeda e depósitos em: & 13.420 & 7.470 & 2.183 & 3.101 \\
\hline$\square$ Outros bancos centrais, BIS e FMI & 250 & 250 & 253 & 253 \\
\hline$\square$ Bancos sediados no Brasil & 101 & - & - & 0 \\
\hline - dos quais: domiciliados no exterior & 101 & - & - & 0 \\
\hline$\square$ Bancos sediados no exterior & 13.070 & 7.220 & 1.931 & 2.848 \\
\hline - dos quais: domiciliados no Brasil & - & - & - & 0 \\
\hline - Posição de reserva no FMI & - & - & - & 0 \\
\hline - DES & 8 & 2 & 1 & 1 \\
\hline - Ouro (inclusive depósitos de ouro) ${ }^{3 /}$ & 683 & 901 & 940 & 954 \\
\hline 口 Volume em mil onças troy & 1.080 & 1.080 & 1.080 & 1.080 \\
\hline Outros ativos de reservas & 685 & 15.905 & 1.913 & 3.728 \\
\hline Q Instrumentos derivativos & -1 & -32 & - & -1 \\
\hline @ Empréstimos a não residentes não bancários ${ }^{4 /}$ & 69 & 58 & 34 & 34 \\
\hline 口 Cédulas e moedas & - & - & - & 0 \\
\hline @ Títulos adquiridos com acordo de recompra ${ }^{5 /}$ & 617 & 15.878 & 1.880 & 3.694 \\
\hline \multicolumn{5}{|l|}{${ }^{1 /}$ Valores marcados a mercado desde novembro de 2000.} \\
\hline \multicolumn{5}{|c|}{$\begin{array}{l}{ }^{2 /} \text { As reservas líquidas ajustadas denominadas em dólares consideram as paridades do mês anterior para mensurar os } \\
\text { ativos denominados em outras moedas que não o dólar norte-americano. Desde a liquidação da dívida junto ao FMI, } \\
\text { ocorrida em dezembro de } 2005 \text {, não mais se aplica esse conceito. }\end{array}$} \\
\hline \multicolumn{5}{|l|}{ 3/ Engloba estoque de ouro financeiro disponível e depósitos a prazo. } \\
\hline \multicolumn{5}{|l|}{${ }^{4 /}$ Inclui valores de créditos de exportação. } \\
\hline & & & & \\
\hline
\end{tabular}




\section{ANEXO C - Indicadores calculados para o nível das Reservas Internacionais}

\section{brasileiras.}

\begin{tabular}{|c|c|c|c|c|c|c|c|c|c|c|}
\hline Dez-00 & 33.011 & 644.984 & 15.061 & 27.420 & 27.234 & 18.530 & $5,1 \%$ & 2,2 & 1,2 & 0,45 \\
\hline Dez-01 & 35.866 & 553.771 & 12.463 & 27.658 & 26.114 & 15.500 & $6,5 \%$ & 2,9 & 1,3 & 0,52 \\
\hline Dez-04 & 52.935 & 663.783 & 17.609 & 18.744 & 34.564 & 29.066 & $8,0 \%$ & 3,0 & 2,8 & 0,64 \\
\hline Dez-05 & 53.799 & 882.439 & 19.510 & 18.776 & 21.553 & 53.438 & $6,1 \%$ & 2,8 & 2,9 & 0,57 \\
\hline Dez-06 & 85.839 & 1.088 .911 & 24.609 & 20.323 & 20.225 & 101.601 & $7,9 \%$ & 3,5 & 4,2 & 0,60 \\
\hline Dez-07 & 180.334 & 1.333 .818 & 34.962 & 38.901 & 23.305 & 214.111 & $13,5 \%$ & 5,2 & 4,6 & 0,65 \\
\hline Dez-08 & 193.783 & 1.573 .321 & 41.904 & 36.465 & 18.949 & 123.089 & $12,3 \%$ & 4,6 & 5,3 & 1,09 \\
\hline
\end{tabular}

Fonte: BCB (séries temporais n. 3546, 4192, 2734, 12504 e nota para a imprensa quadro 51); CVM (investidor estrangeiro, valor da carteira).

RI - Reservas Internacionais

PIB - Produto Interno Bruto

Div. Ext. CP - Dívida Externa de Curto Prazo

Serv. Div. MLP - Serviço da Dívida de Médio e Longo Prazo que vencem no curto prazo.

*Pública e Privada, com vencimento em 12 meses. Fonte: BACEN.

** Pública e Privada, exclui o FMI. Obtida indiretamente a partir do indicador de endividamento externo "Reservas Internacionais/Dívida Exetrna de Curto Prazo Residual" disponibilizado pelo BACEN.

*** Inclui Renda Fixa Pública e Privada, Ações e Derivativos. Fonte: CVM.

**** Regra Greenspan/Guidotti, nível ideal (mínimo) $=1$

Obs: Reservas pelo critério de liquidez, Importações CIF. 